\title{
Betamethasone Increases Pulmonary Compliance in Part by Surfactant-Independent Mechanisms in Preterm Rabbits
}

\author{
JOHN M. FIASCONE, HARRIS C. JACOBS, FERNANDO R. MOYA, MARK R. MERCURIO, AND \\ DAVID M. LIMA
}

Department of Pediatrics, Yale University School of Medicine, New Haven, Connecticut 06510

\begin{abstract}
Antenatal exposure to corticosteroids is known to increase the pulmonary compliance of preterm animals. We wished to determine whether this was due solely to alteration in lung surfactant content. Rabbit does were injected with either vehicle alone or betamethasone on days 25 and 26 of gestation. Fetuses were delivered at $\mathbf{2 7}$ days and given either $\mathbf{5 0 \%}$ lactated Ringer's or intratracheal natural surfactant prior to their first breath. Fetuses were mechanically ventilated at a tidal volume of $12 \mathrm{ml} / \mathrm{kg}$ for $60 \mathrm{~min}$ with periodic compliance measurements. Following ventilation an alveolar lavage was collected for phosphatidylcholine determination. Some fetuses did not undergo ventilation but had saline compliance studies instead. Fetuses given intratracheal surfactant had a higher dynamic compliance than fetuses exposed to antenatal corticosteroids $(0.55 \pm 0.01$ versus $0.48 \pm 0.02 \mathrm{ml} / \mathrm{cm}$ $\mathrm{H}_{2} \mathrm{O} / \mathrm{kg}$, respectively). Fetuses exposed to antenatal corticosteroids and given intratracheal surfactant had a dynamic compliance $(0.66 \pm 0.02)$ that was greater than those exposed to either single therapy. This was found despite an alveolar surfactant content equal to that in fetuses receiving intratracheal surfactant alone. Saline compliance at birth was significantly greater for fetuses exposed antenatally to steroids. These data imply the existence of a nonsurfactant mechanism by which antenatal corticosteroids increase fetal pulmonary compliance. (Pediatr Res 22:730-735, 1987)
\end{abstract}

\section{Abbreviations}

RDS, respiratory distress syndrome PC, phosphatidylcholine

ANOVA, analysis of variance

Animals and humans delivered prematurely characteristically exhibit low pulmonary compliance in comparison to their fullterm counterparts (1-5). Multiple studies indicate that a deficiency of pulmonary surfactant is an important contributing factor in producing this low lung compliance in preterm animals and humans (1-8). Intratracheal administration of natural surfactant increases the pulmonary compliance of preterm animals

Received May 20, 1987; accepted August 11, 1987.

Correspondence and reprint requests John M. Fiascone, M.D., Department of Pediatrics, Yale University School of Medicine, 333 Cedar Street, New Haven, CT 06510.

Supported by BRSG Grant RR 05358 awarded by the Biomedical Research Support Grant Program, Division of Research Resources, NIH: by an NIH New Investigator Research Award HL/HD 33348; and by a research grant from the Charles H. Hood Foundation. and ameliorates the course of human RDS (1-4, 6-10). These latter findings further support the concept that a deficiency of pulmonary surfactant is central to the pathogenesis of RDS.

Antenatal administration of corticosteroids results in a significant improvement in the pulmonary compliance of animals delivered prematurely and a reduction in the incidence of RDS in preterm humans (11-21). A large body of experimental evidence attributes this effect to stimulation of the surfactant system $(12,15,18,22-24)$. However, evidence exists that there are other pulmonary changes induced by antenatal exposure to corticosteroids $(11,16,22)$. Antenatal administration of corticosteroids to fetal rabbits accelerates morphologic development of the lung by $1 \frac{1}{2}$ days compared to control fetuses $(25,26)$. In vitro studies using dexamethasone in organ cultures support these findings $(27,28)$. Altered protein synthesis in fetal lung induced by corticosteroids has also been reported (28) including an alteration in the collagen/elastin ratio in the rhesus monkey fetus (11).

We hypothesized that an alteration in nonsurfactant aspects of the premature lung was a significant component in the increased pulmonary compliance found after antenatal administration of corticosteroids. If this were true then combination therapy with antenatal corticosteroids and intratracheal natural surfactant would produce a greater increase in pulmonary compliance than surfactant replacement therapy alone. Additionally we would also expect that antenatal exposure to corticosteroids would produce an increase in the saline compliance of lungs compared to controls as this is generally believed to be a surfactant-independent phenomenon (29). We tested our hypothesis in a model using prematurely delivered fetal rabbits. This work has been previously published in part in abstract form $(30,31)$.

\section{METHODS}

Animals. Date-mated New Zealand White rabbits were used for all experiments. One hundred thirty-one fetuses were used in the course of the experiments described herein. All fetuses were delivered at 27 days gestation with time of mating taken as zero time (term $=31$ days). This gestational age was chosen based on preliminary studies that showed that fetuses at this gestation have a low lung compliance compared to term rabbits and that they have a consistent severity of lung disease. Does were injected 48 and $24 \mathrm{~h}$ prior to surgical delivery with $0.33 \mathrm{ml} / \mathrm{kg}$ of either lactated Ringer's solution (controls) or $6 \mathrm{mg} / \mathrm{ml}(0.2 \mathrm{mg} / \mathrm{kg})$ of betamethasone (Schering). The dose of betamethasone and timing of injection were based on previously published data in rabbits (24). On the day of delivery does were anesthetized with intravenous ketamine $(15 \mathrm{mg})$ and pentobarbital $(240 \mathrm{mg})$, an endotracheal tube was placed via a tracheotomy and mechanical ventilation of the doe was initiated. All does were ventilated with $40 \% \mathrm{O}_{2}$ and a peak inspiratory pressure and rate which produced an arterial pH between 7.30 and 7.45. Fetuses were delivered in 
rapid sequence by cesarean section and weighed immediately. Some fetuses were sacrificed at birth. prior to the first breath. and underwent a thorough alveolar lavage for phosphatidycholine determination. Another group of fetuses was sacrificed at birth, prior to the first breath, and was used for determination of static saline pulmonary compliance or lung wet to dry weight measurements as described below. A third group of fetuses was prepared for mechanical ventilation. They were delivered, weighed, and had endotracheal tubes placed via a tracheotomy. Fach fetus was randomly given $3.3 \mathrm{ml} / \mathrm{kg}$ of either $1: 1$ lactated Ringer's in water $(\mathrm{v} / \mathrm{v})$ or surfactant which was isolated from the alveolar wash of adult rabbits $(1,32)$ and suspended in the same solution. The concentration of surfactant was adjusted to provide $100 \mathrm{mg}$ surfactant lipid per $\mathrm{kg}$. This dose was chosen because preliminary results indicated that no further increase in compliance was achieved with larger doses of surfactant and because it is consistent with that used by other investigators (8). In order to obtain an even distribution of surfactant within the lungs all injections were given prior to the first breath and no air bubbles preceded the injection solution (3.3).

Mechanical ventilation. Following intratracheal injection. fetuses prepared for mechanical ventilation were connected to a specially constructed time-cycled, pressure-limited fetal rabbit ventilator which allowed simultaneous ventilation of up to eight fetuses (Fig. 1). This ventilator is a modification of that used by lachmann el al. (34) which allowed us to independently vary the peak inspiratory pressure received by each fetus. The driving force behind the fetal rabbit ventilator was a Bear Cub ventilator (Bear Medical Instruments). The Bear (ub was set to provide ventilation with $100 \% \mathrm{O}_{2}$ at a rate of 35 breaths $/ \mathrm{min}$, an inspiratory time of $0.9 \mathrm{~s}$, peak inspiratory pressure of $35 \mathrm{~cm} \mathrm{H}_{2} \mathrm{O}$. and an end expiratory pressure of () $\mathrm{cm} \mathrm{H}_{2} \mathrm{O}$. This output from the Bear (ub was divided into eight parallel circuits. Each circuit contains a water column whose height ean be varied independently allowing independent adjustment of the peak inspiratory pressure provided to each fetus up to a maximum of $35 \mathrm{~cm} \mathrm{H}_{2} \mathrm{O}$

Fetuses were given $0.2 \mathrm{mg}$ pancuronium bromide by intraperitoneal injection and each fetus was sealed in an individual body plethysmograph (Fig. 1). Flow into and out of each body plethysmograph was measured using a calibrated pneumotachygraph and differential pressure transdueer (Validyne mode DP45). Flow was electronically integrated with a respiratory flow integrator (Validyne model FV156) to obtain a tidal volume which was recorded on a Sanborn strip chart recorder. A second differential pressure transducer (Sanborn model 270) with one end open to the atmosphere was used to measure pressure proximal to the endotracheal tube. This pressure was recorded simultaneously with tidal volume on the strip chart recorder. Fetuses were initially ventilated with the ventilatory parameters described above. During the experiment only the peak inspiratory pressure was changed by altering the height of water in the water columns and this was altered in a manner so as to maintain a constant tidal volume of $12 \mathrm{ml} / \mathrm{kg}$ body weight. This tidal volume was chosen based on our preliminary investigations which showed that blood obtained by direct cardiac puncture from fetuses ventilated in this manner had a $\mathrm{PCO}_{2}$ consistently less than $45 \mathrm{~mm} \mathrm{Hg}$. At 15-min intervals for $1 \mathrm{~h}$. peak inspiratory pressure and tidal volume were recorded and used to calculate a dynamic pulmonary compliance which was normalized to body weight. $A t$ the end of $1 \mathrm{~h}$, after a final peak inspiratory pressure and tidal volume determination. fetuses were sacrificed. Some fetuses underwent a thorough alveolar lavage while the lungs of others were used to determine the ratio of wet lung weight to dry lung weight (see below). At the time of alveolar lavage all lungs underwent inspection for uniformity of inflation. Fetuses given natural surfactant uniformly exhibited even pulmonary acration without areas of visible atelectasis.

Static saline compliance studies. Some fetuses sacrificed at birth and prior to the first breath were used to measure static saline compliance at $10 \mathrm{~cm} \mathrm{H_{2 }} \mathrm{O}$ which was defined as total lung

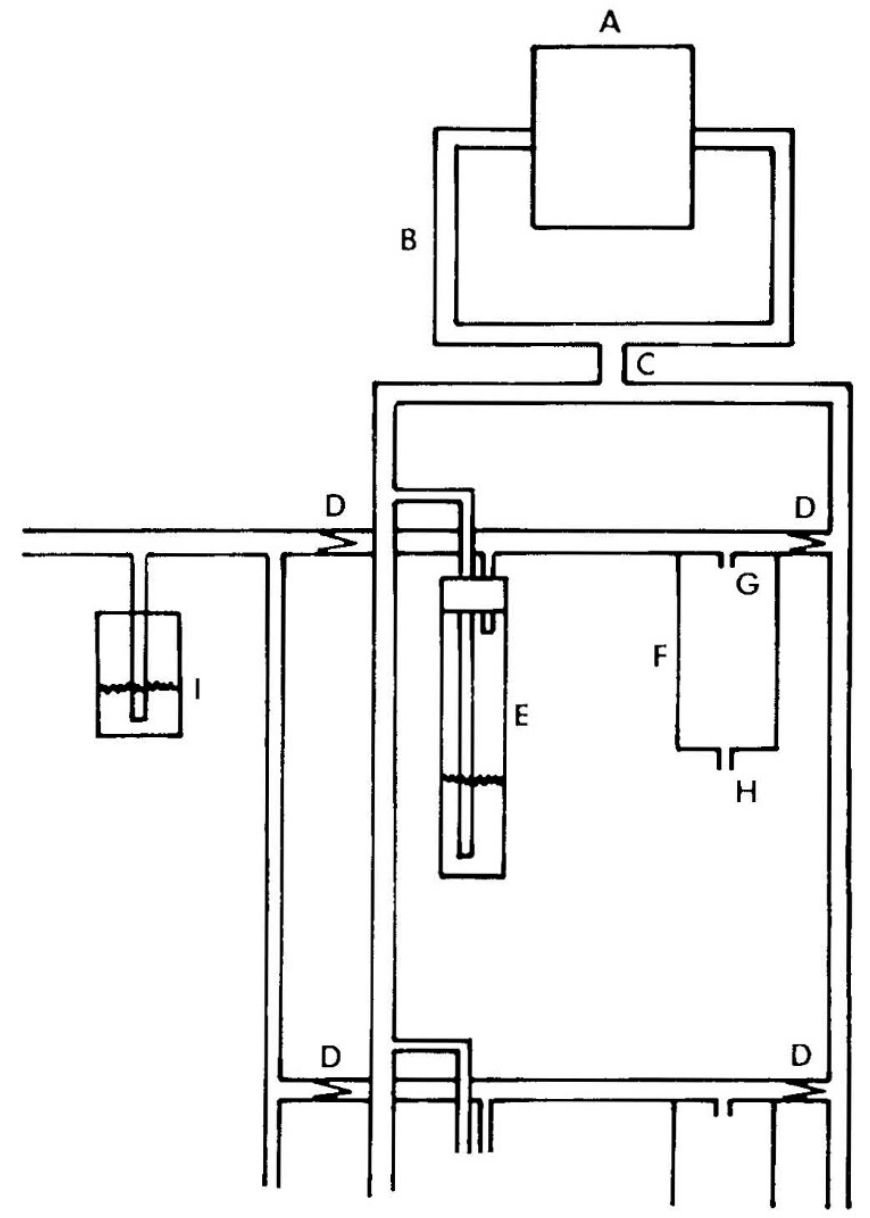

Fig. 1. Schematic diagram of tetal rabbit ventilator. a. Bear ('ut Ventilator set to deliver $100 \%$ O. peak inspiratory pressure $35 \mathrm{~cm} H$, () end expiratory pressure $0 \mathrm{~cm} \mathrm{H}_{2} \mathrm{O} .35$ breaths/min and an inspiratory time of $0.9 \mathrm{~s}: b$. main ventilator circuit: $a, 10-\mathrm{mm}$ endotracheal tube

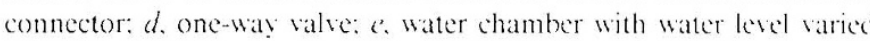
for each fetus to adjust the inspiratory pressure delivered: / fetal bod plethysmograph: $g$. fetal endotracheal tube connector: h. port to measure flow (tidal volume): and $i .2 \mathrm{~cm} \mathrm{H}, \mathrm{O}$ release valve in fresh (), blow-ho circuit.

capacity. This pressure was chosen because no areas of lung wero atelectatic by visual inspection and no secpage of saline onto the lung surface was apparent at this pressure. Also, in preliminary studies lung rupture was seen consistently at pressures greater than $15 \mathrm{~cm} \mathrm{H} \mathrm{H}_{2} \mathrm{O}$. A tracheotomy was performed following sacrifice and fetuses were attached without any intervening air bubbles to a saline-filled manometer system containing a syringe attached through a $T$-connector. The chest was carefully opened. the ribs cut away. and the diaphragm was cut so that saline compliance would reflect only properties of lung tissue in all fetuses. The lungs were left in situ and inflated manually over $10-15 \mathrm{~s}$ with saline to a pressure of $10 \mathrm{~cm} \mathrm{H}_{2} \mathrm{O}$. I ungs were allowed to equilibrate for $2 \mathrm{~min}$ during which time the pressure dropped and pulmonary expansion could be seen to continue. After $2 \mathrm{~min}$ the lungs were reinfused with saline over $[0-15 \mathrm{~s}$ until the manometer again displaved a pressure of $10 \mathrm{~cm} \mathrm{H}_{3} \mathrm{O}$. Total volume infused was recorded. The process was then reversed by withdrawing saline over 1()-15 s until the distending pressure was reduced to zero $\mathrm{cm} \mathrm{H}_{2} \mathrm{O}$. Again 2 min were allowed for equilibration during which time the pressure rose stightly and the lungs showed a slight further deflation. Alter $2 \mathrm{~min}$ the distending pressure again was reduced to zero $\mathrm{cm} \mathrm{H}$ () over l() $15 \mathrm{~s}$. The total volume withdrawn was recorded. This entire process of inflation and deflation was then repeated with volumes 
recorded as above. The residual lung volume after the first inflation-deflation cycle was added to the volume infused during the inflation portion of the second cycle. This volume was then used to calculate a static saline pulmonary compliance. No saline leaks were observed in the lungs of any fetus.

Lipid analysis. Some ventilated and some unventilated fetuses were subjected to a thorough alveolar lavage as previously described (35). Briefly, the chest was opened and saline infused until the lungs were completely distended. This saline was withdrawn and reinfused three times. As much as possible was collected on the third withdrawal and collected in a graduated tube. This process was repeated four more times with all collected volumes combined and referred to as the alveolar lavage. One $\mathrm{ml}$ of alveolar lavage was saved for protein determination. Lipids were extracted from the remainder of the lavage using 2:1/ chloroform:methanol. PC was isolated by thin-layer chromatography (36) and quantitated by a phosphorous assay (37). From the original volume of alveolar lavage and the volume extracted the total alveolar PC per kg of body weight was calculated.

Protein determinations. The portion of the alveolar lavage fluid saved for determination of protein content was assayed according to the method of Lowry et al. (38). From the recorded dilutions at each step the concentration of protein in the volume assayed was used to calculate an alveolar protein content per $\mathrm{kg}$ of body weight.

Wet to dry weight ratios. Either at birth or following $1 \mathrm{~h}$ of mechanical ventilation some fetuses had their chests opened and $0.2 \mathrm{ml}$ of blood was obtained in a heparinized syringe by direct heart puncture. These lungs were then immediately removed. The left lung of each fetus was weighed and dried in an oven at $70^{\circ} \mathrm{C}$ for $48 \mathrm{~h}$ by which time the weight had stabilized. The other lung was weighed and homogenized in $1.0 \mathrm{ml}$ of distilled water. Blood, $0.1 \mathrm{ml}$, was weighed then dried in an oven at $70^{\circ} \mathrm{C}$ to obtain a dry weight as for the left lung. The supernatant of the homogenized lung following centrifugation and the remaining $0.1 \mathrm{ml}$ of blood were analyzed by the cyanomethemoglobin method to determine the volume of blood remaining in the lungs per $g$ wet weight (39). This value and the dry weight of blood per $\mathrm{ml}$ were used to correct the wet and dry weights of the left lung for the contribution due to intravascular blood. Corrected values were used to obtain a true wet to dry weight ratio for the left lung of each fetus.

Determination of fetal sex. Fetal sex was determined independently by two observers based on location and appearance of gonadal structures within the fetal abdomen or pelvis (40).

Statistical analysis. Comparisons among the four groups of mechanically ventilated fetuses: control, corticosteroid-exposed, natural surfactant alone, and combined therapy (corticosteroidexposed and natural surfactant) were accomplished by ANOVA followed by a Student-Newman-Keuls test. Static saline pulmonary compliance in unventilated control and corticosteroid-exposed fetuses were compared by an unpaired $t$ test. Differences between groups were considered significant for $p<0.05$.

During mechanical ventilation animals were eliminated from the experiment if they developed a pneumothorax. Pneumothoraces were obvious on inspection and confirmed by postmortem examination. Animals developing pulmonary leaks during alveolar lavage were excluded from PC and protein analysis. Individual values were eliminated from the data pool if they were more than two SDs from the mean of their experimental group. No more than two animals were eliminated from any group. All values shown are mean \pm SEM.

\section{RESULTS}

Mechanical ventilation. Fetuses were delivered at intervals of about $5 \mathrm{~min}$. All fetuses were viable at the time of delivery. The mean time from delivery to initiation of ventilation was $2.9 \pm$ $0.9 \mathrm{~min}$ and was not different for the four ventilation groups. Animals that did not develop a pneumothorax remained pink and well perfused throughout the $60 \mathrm{~min}$ of ventilation. No differences were found between male and female fetuses in any part of this study. Birth order did not influence pulmonary compliance (data not shown).

Antenatal corticosteroid exposure significantly reduced fetal body weight compared to controls $(21.1 \pm 0.4$ versus $29.9 \pm 0.8$ $\mathrm{g}, p<0.05$, Table 2) and also, as expected from previous investigations, lowered the ratio of wet lung weight to body weight by fourteen percent $(41,42)$. The nature of the alveolar lavage procedure precluded our obtaining wet lung weights on all fetuses. For this reason compliance values have been expressed in terms of fetal body weight rather than lung weight. It is important to note that because steroid exposure reduces the lung weight to body weight ratio, normalization of compliances to lung weight rather than body weight would have increased differences between steroid-exposed and control animals.

All four groups of fetuses (control, corticosteroid-exposed, natural surfactant treated, and combined therapy) were equivalently ventilated (Fig. $2 A$ ). Intended tidal volumes were established within 30 min for all fetuses and very little change in peak inspiratory pressure was required beyond this time. The mean tidal volume at $60 \mathrm{~min}$ was close to the intended value of 12.0 $\mathrm{ml} / \mathrm{kg}$ for each group and the values were very similar for the different groups.

Peak inspiratory pressures required to maintain the intended tidal volumes varied with the treatment received. At $60 \mathrm{~min}$ of age, control fetuses required the highest pressures $(28.4 \pm 0.7 \mathrm{~cm}$ $\mathrm{H}_{2} \mathrm{O}$ ) while fetuses receiving the combination of antenatal exposure to betamethasone and intratracheal natural surfactant at birth required the lowest pressures $\left(19.1 \pm 0.7 \mathrm{~cm} \mathrm{H}_{2} \mathrm{O}\right.$ ) (Fig. $2 B$ ). These relationships are best compared by dividing tidal volume by peak inspiratory pressure to obtain dynamic compliance $\left(\mathrm{ml} / \mathrm{cm} \mathrm{H} \mathrm{H}_{2} \mathrm{O} / \mathrm{kg}\right.$ body weight).

Within each of the four ventilated groups of fetuses, dynamic compliance normalized to body weight was nearly constant for the duration of the experiment (Fig. 3). At $60 \mathrm{~min}$, the mean compliance of control fetuses $\left(0.42 \pm 0.01, \mathrm{ml} / \mathrm{cm} \mathrm{H}_{2} \mathrm{O} / \mathrm{kg}\right)$ was significantly less than that of the other three groups. Animals
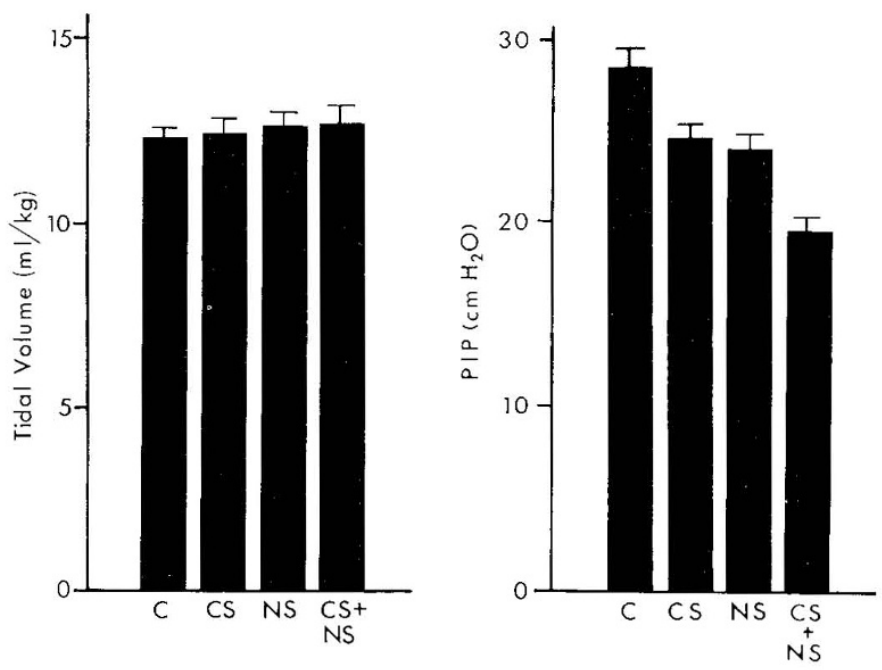

Fig. 2. Tidal volume and peak inspiratory pressure at $60 \mathrm{~min}$. $A$, tidal volume (mean \pm SEM) is given as $\mathrm{ml} / \mathrm{kg}$ body weight for each group of fetuses. $C$, control $(n=24) ; C S$, antenatal corticosteroid exposure $(n=$ $22)$; NS, intratracheal natural surfactant at birth $(n=17) ; C S+N S$, combined antenatal corticosteroid exposure and intratracheal natural surfactant at birth $(n=14)$. Mean tidal volumes for the four groups were close to the intended value of $12 \mathrm{ml} / \mathrm{kg}$ and were not statistically different for the four groups. $B$, peak inspiratory pressure (mean $\pm \mathrm{SEM}$ ) is given in $\mathrm{cm} \mathrm{H}_{2} \mathrm{O}$ for each of the four groups. Symbols are the same as in $A$. Note that control fetuses required more pressure than the other three groups and that fetuses receiving combination therapy required less pressure than those receiving only corticosteroid or only surfactant. 
given surfactant had a mean compliance significantly higher than that of animals exposed to corticosteroids $(0.55 \pm 0.01$ rersus $0.48 \pm 0.02 \mathrm{ml} / \mathrm{cm} \mathrm{H}_{2} \mathrm{O} / \mathrm{kg}$. respectively). Fetuses both exposed to corticosteroids and receiving surfactant (combined therapy) had a mean compliance $\left(0.66 \pm 0.02 \mathrm{ml} / \mathrm{cm} \mathrm{H}_{2} \mathrm{O} / \mathrm{kg}\right.$ ) which was significantly larger than that of animals only receiving surfactant or only exposed to corticosteroids $(p<0.01)$. That is the combined therapy was more effective than either single therapy and, in this experiment, the mean percent increase of combined therapy over controls was slightly greater than additive.

Alveolar lavage $P C^{\prime}$ and protein. To determine whether the improved dynamic compliance following antenatal exposure to betamethasone could be explained by its effect on the surfactant system, we measured alveolar lavage PC in control and corticosteroid-exposed fetuses sacrificed at birth and in the four groups of ventilated fetuses (Table 1). Antenatal exposure to corticosteroids increased the amount of alveolar lavage PC found at birth by about $50 \%$. After I h of mechanical ventilation, control fetuses increased their alveolar lavage $P C$ content from the value at birth by almost 12 -fold to $6.2 \pm 1.6 \mu \mathrm{mol} / \mathrm{kg}$. This value was not statistically different than the $3.1 \pm 0.6 \mu \mathrm{mol} / \mathrm{kg}$ recovered from steroid-exposed fetuses ventilated for $1 \mathrm{~h}$ despite a significant difference in dynamic compliance between these two groups Animals that received exogenous intratracheal natural surfactant had alveolar lavage PC contents in striking excess compared to all other groups. Fetuses receiving intratracheal natural surfactant alone had the same alveolar lavage $\mathrm{PC}$ content as those receiving

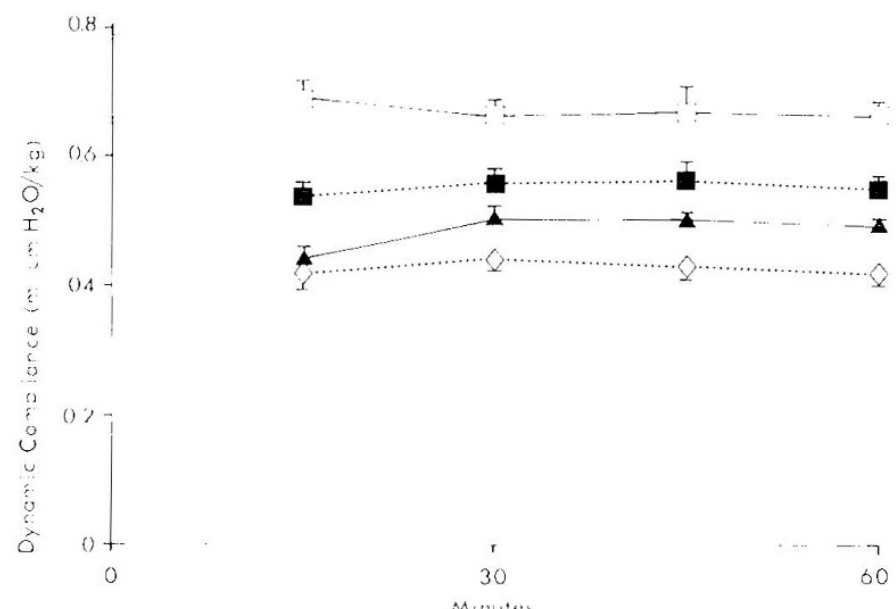

Fig. 3. Dynamic compliance versus time. Open diamonds. control: closed triangles, antenatal corticosteroid exposure: closed squares. intratracheal natural surfactant at birth; open squares, combined therapy with antenatal corticosteroid exposure and intratracheal natural surfactant at birth. Dynamic compliance in any group showed little variation over time. At $60 \mathrm{~min}$ combined therapy produced a significantly greater dynamic compliance than either single therapy alone $(p<0.01)$ and in fact the percent increase was approximately additive. Surfactant treatment was superior to corticosteroid exposure $(p<0.05)$. while fetuses receiving either alone was better than controls $(p<0.01)$. combined therapy with both natural surfactant and antenatal corticosteroids: $75.4 \pm 10.0$ rersus $71.2 \pm 6.4 \mu \mathrm{mol} \mathrm{PC} / \mathrm{hg}$. respectively (Cable 1). Despite no differences in alveolar lavage $P C$ content between these two groups. the combination of antenatal corticosteroids and intratracheal administration of natural surfactant at birth increased dynamic compliance compared to either therapy alone (Fig. 3).

The amount of protein recovered by alveolar lavage showed a fairly large variation within each group as has been reported previously (data not shown) (43). This variation precluded any meaningful conclusion about the effect of antenatal corticosteroids on protein leak.

Static saline lung compliance. The saline compliance of corticosteroid-exposed fetuses sacrificed at birth was significantly greater $(p<0.01)$ than that of controls: $5.64 \pm 0.56(n=10)$ versus $4.25 \pm 0.23(n=19) \mathrm{ml} / \mathrm{cm} \mathrm{H}_{2} \mathrm{O} / \mathrm{kg}$. respectively. If saline compliances were normalized to lung weight instead of body weight the magnitude of the difference between groups would be enhanced.

Lung wet to dry weight ratios. One potential mechanism unrelated to surfactant synthesis by which antenatal corticosteroid exposure might alter pulmonary compliance would be by decreasing extravascular lung water content. If this were to oceur then the ratio of wet lung weight to dry lung weight should be different between corticosteroid-exposed and control features. Table 2 contains the results obtained when wet to dry lung weight ratios. corrected for intravascular blood content, are performed on ventilated and unventilated lungs in steroid-exposed and control fetuses. Administration of natural surfactant was not found to alter this ratio. The only significant difference found is a reduced ratio in unventilated. steroid-exposed fetuses sacriticed at birth. After $1 \mathrm{~h}$ of mechanical ventilation. however. this difference is no longer detectable

\section{DISCUSSION}

It is widely accepted that antenatal administration of corticosteroids increases pulmonary compliance in preterm animals through stimulation of the pulmonary surfactant system $(15,18$. 22-24). In an analogous manner it is believed that this effect is responsible for the reduced incidence of RDS seen in humans following maternal therapy with corticosteroids given in anticipation of premature delivery (19-21). However, several studies suggest that part of the improvement in pulmonary compliance seen in animal models due to antenatal corticosteroids is mediated by effects other than those on pulmonary surfactant (11. 13. 14, 16, 17, 46). If antenatal corticosteroid therapy improves lung compliance only by increasing the size of the alveolar surfactant pool, then when alveolar pool sizes of surfactant are equal, combined therapy with corticosteroids and natural surfactant should be equivalent to natural surfactant replacement therapy alone.

We believe that the rabbit fetuses used in this study provide a fair test of this hypothesis. The values obtamed for alveolar surfactant content in control fetuses sacrificed at birth are in close agreement with those reported in a recently published study (44). Also, rabbit fetuses sacrificed at birth prior to any ventila-

Table 1. Hoveolar lavage P' content for experimental groups (mean \pm SI:VH)

\footnotetext{
(ontrol. sacrificed at birth

Alveolar lavage P' content $(\mu \mathrm{mol} / \mathrm{kg})$ $0.53 \pm 0.03 *$ $n=13$
Steroid-exposed sacrificed at birth

$* p<0.05$ control iersus corticosteroid groups.

$\dagger p<0.01$ versus control and corticosteroid groups at birth.

$\ddagger p<0.01$ versus control and corticosteroid groups.
}

Control after mechanical ventilation

$6.2 \pm 1.6+$

$n=15$
Intratracheal

Antenatal-steroid exposed after mechanical ventilation

$3.1 \pm 0.6 \%$ $n=12$ surfactant at birth after mechanical ventilation

$75.37 \pm 10.01+\mathrm{t}$ $n=9$
Combined therans atter mechanical ventilation

$71.24 \pm 0.41+1$ $n=7$ 
Table 2. Body wt, lung wt, and ratio of lung wet wt to dry wt for control and corticosteroid exposed fetuses*

\begin{tabular}{|c|c|c|c|c|c|c|}
\hline & \multicolumn{3}{|c|}{ Control } & \multicolumn{3}{|c|}{ Corticosteroid exposed } \\
\hline & $\begin{array}{l}\text { Birth wt } \\
(\mathrm{g})\end{array}$ & $\begin{array}{l}\text { Lung wet wt } \\
\text { (g) }\end{array}$ & $\begin{array}{c}\text { Wet/dry } \\
\text { ratio }\end{array}$ & $\begin{array}{l}\text { Birth wt } \nmid \\
\text { (g) }\end{array}$ & $\begin{array}{l}\text { Lung wet wt } \\
(\mathrm{g})\end{array}$ & $\begin{array}{l}\text { Wet/dry } \\
\text { ratio }\end{array}$ \\
\hline Ventilated & $\begin{array}{c}29.9 \pm 0.8 \\
n=41\end{array}$ & $\begin{array}{c}0.466 \pm 0.037 \\
n=7\end{array}$ & $\begin{array}{c}8.98 \pm 0.18 \\
n=7\end{array}$ & $\begin{array}{c}21.1 \pm 0.4 \\
n=38\end{array}$ & $\begin{array}{c}0.307 \pm 0.031 \\
n=9\end{array}$ & $\begin{array}{c}8.86 \pm 0.37 \\
n=9\end{array}$ \\
\hline Unventilated & $\begin{array}{c}30.8 \pm 0.8 \\
n=20\end{array}$ & $\begin{array}{c}1.153 \pm 0.063 \\
n=20\end{array}$ & $\begin{array}{c}9.56 \pm 0.21 \\
n=20\end{array}$ & $\begin{array}{c}20.6 \pm 0.8 \\
n=10\end{array}$ & $\begin{array}{c}0.635 \pm 0.072 \\
n=11\end{array}$ & $\begin{aligned} 8.21 & \pm 0.18+ \\
n & =11\end{aligned}$ \\
\hline
\end{tabular}

* Lung wet weights not compared.

$\dagger p<0.05$ versus equivalent control.

$\ddagger p<0.01$ versus unventilated control.

tion showed a significant increase in alveolar lavage PC content in response to antenatal corticosteroids. Surfactant pool sizes in those fetuses not given surfactant at birth (control and corticosteroid-exposed fetuses) increased after $1 \mathrm{~h}$ of ventilation compared to equivalently treated fetuses sacrificed prior to the first breath. This increase was consistent with previous observations in preterm and term lambs, preterm monkeys $(17,35,45)$ and in premature rabbits $(18,43,46)$.

We found a similar although not equal improvement in dynamic compliance compared to controls when corticosteroids or natural surfactant were used alone. However, combining these two therapies increased dynamic compliance over either individual therapy despite equivalent pool sizes for the combined therapy group and the group given only natural surfactant.

It is believed that surfactant acts at an alveolar air-water interface to improve compliance in the air filled lung (47). Thus pressure-volume characteristics of lungs inflated with saline (as opposed to air) would not be influenced by the presence or absence of alveolar surfactant and any treatment that produces an increase in saline lung compliance would do so by a nonsurfactant dependent mechanism. We chose to define total lung capacity as the lung volume at a pressure of $10 \mathrm{~cm} \mathrm{H}_{2} \mathrm{O}$ when inflated with saline since by visual inspection lungs were fully inflated at this pressure. Also, as reported by others attempting saline compliance in small preterm animals (17), the lungs rupture at higher pressures. There was a significant increase in the saline compliance of lungs of fetuses exposed antenatally to corticosteroids compared to control fetuses consistent with the results of Mitzner et al. (17). These findings support the hypothesis that corticosteroids alter lung compliance in part through a nonsurfactant-dependent mechanism.

Steroid exposure did decrease the lung wet to dry weight ratio in animals sacrificed at birth. This would be consistent with a decrease in pulmonary extravascular water. However, this difference in ratios was no longer present after $60 \mathrm{~min}$ of mechanical ventilation. Although this information is not conclusive it raises the possibility that decreased extravascular pulmonary water present at birth may still influence dynamic compliance at $1 \mathrm{~h}$ of age.

We conclude that antenatal corticosteroids improved lung compliance in these preterm rabbit fetuses in large part by a mechanism independent of their effect on the surfactant system consistent with the earlier reports of Mitzner and coworkers (11, 13, 14, 16-18). This nonsurfactant mechanism may involve elements of lung connective tissue or shifts in extravascular lung water. We further conclude that in the premature rabbit model of human RDS, combined therapy with antenatal corticosteroids and intratracheal natural surfactant is superior to either therapy alone. This suggests, as reported in a recent abstract (48), that when exogenous surfactant becomes available for clinical use there may still be additional benefits from antenatal administration of corticosteroids.

Acknowledgment. The authors thank Bear Medical Instruments for the use of a Bear Cub ventilator.

\section{REFERENCES}

1. Adams FH, Towers B, Osher AB, Ikegami M, Fujiwara T, Nozaki M 1978 Effects of tracheal instillation of natural surfactant in premature lambs. I. Clinical and autopsy findings. Pediatr Res 12: $11-848$

2. Egan EA, Notter RH, Kwong MS, Shapiro DL 1983 Natural and artifical lung surfactant replacement therapy in premature lambs. J Appl Physiol 55:875883

3. Jobe AM. Ikegami M, Glatz T, Yoshida Y, Diakomanolis E, Padbury J 1981 Duration and characteristics of treatment of premature lambs with natural surfactant. J Clin Invest 67:370-375

4. Lachmann B, Berggren P, Curstedt T, Grossman G, Robertson B 1982 Combined effects of surfactant substitution and prolongation of inspiratory phase in artificially ventilated premature newborn rabbits. Pediatr Res 16.921-927

5. Avery ME and Mead J 1959 Surtace properties in relation to atelectasis and hyaline membrane disease. Am J Dis Child 97:517-523

6. Kwong MS, Egan EA, Notter RH, Shapiro DL 1985 Double-blind clinical trial of calf lung surfactant extract for the prevention of hyaline membrane disease in extremely premature infants. Pediatrics $76: 585-592$

7. Jacobs H, Jobe A, Ikegami M, Glatz T, Jones S, Barajas L 1982 Premature lambs rescued from respiratory failure with natural surfactant: clinical and biophysical correlates. Pediatr Res 16:424-429

8. Ikegami M, Adams FH, Towers B. Osher AB 1980 The quantity of natural surfactant necessary to prevent the respiratory distress syndrome in lambs. Pediatr Res 14:1082-1085

9. Hallman M, Merritt TA, Jarvenpaa AL, Boynton B, Mannino F, Gluck L. Moore T, Edwards D 1985 Exogenous human surfactant for treatment of severe respiratory distress syndrome: a randomized prospective clinical trial. J Pediatr 106:963-969

10. Enhorning G, Sherman A, Possmayer F, Dunn M, Chen C, Mulligan J 1985 Prevention of neonatal respiratory distress syndrome by tracheal instillation of surfactant: a randomized clinical trial. Pediatrics 76:145-153

11. Beck JC. Mitzner W, Johnson JWC, Hutchins GM, Foidart JM, London WT, Palmer AE, Scott R 1981 Betamethasone and the rhesus fetus: effects on lung morphometry and connective tissue. Pediatr Res 15:235-240

12. DeLemos RA, Shermeta DW, Knelson JH, Kotas R. Avery ME 1970 Accelcration of pulmonary surfactant in the fetal lamb by administration of corticosteroids. Am Rev Respir Dis 102:459-461

13. Johnson JWC, Mitzner W, London WT, Palmer AE, Scott R 1979 Betamethasone and the rhesus fetus: multisystemic effects. Am J Obstet Gyneco 133:677-684

14. Kessler DL, Truog WE. Murphy JH, Palmer S, Standaert TA, Woodrum DE Hodson WA 1982 Experimental hyaline membrane disease in the premature monkey. Effects of antenatal dexamethasone. Am Rev Respir Dis 126:62 69

15. Kotas RV, Avery ME 1971 Accelerated appearance of pulmonary surfactant in the fetal rabbit. J Appl Physiol 30:358-361

16. Mitzner W, Johnson JWC, Beck J, London W. Sly D 1982 Influence of betamethasone on the development of mechanical properties in the fetal rhesus monkey lung. Am Rev Respir Dis 125:233-238

17. Mitzner W, Johnson JWC, Scott R, London WT, Palmer AE 1979 Effect of betamethasone on pressure-volume relationship of fetal rhesus monkey lung. J Appl Physiol 47:377-382

18. Ward JA, Erenberg A, Roberts RJ 1983 Postnatal increase in airway surfactant in the premature rabbit exposed in utero to betamethasone. Dev Pharmacol Ther 6:388-403

19. Liggins GC. Howie RN 1972 A controlled trial of antepartum glucocorticoid treatment for prevention of the respiratory distress syndrome in premature infants. Pediatrics 50:515-525

20. Papageorgiou AN, Desgranges MF, Masson M, Colle E, Shatz R, Gelfand MM 1979 The use of antenatal betamethasone in the prevention of respiratory distress syndrome: a controlled double-blind study. Pediatrics 63:73-79

21. Taeusch HW, Frigoletto F, Kitzmiller J, Avery ME, Hehre A, Fromm B Lawson E. Neff RK 1979 Risk of respiratory distress syndrome after prenatal dexamethasone treatment. Pediatrics 63:64-72

22. Robert MF, Bator AT, Tacusch HW 1975 Pulmonary pressure-volume relationships after corticotropin (ACTH) and saline injections in fetal rabbits. Pcdiatr Res 9:760-762

23. Rooney SA, Gobran L, Gross I, Wai-Lee TS, Nardone LL, Motoyama EK 
1976 Studies on pulmonary surfactant. Feffects of cortisol administration to fetal rabbits on lung phospholipid content. composition and biossnthesis. Biochim Biophys Acta 45():12:-1.30)

24. Rooney SA Giobran II. Marino PA Maniscalco WM Gross 1979 Etfiects of betamethasone on phospholipid content, composition and biosynthesis in the fetal rabbit lung. Biochim Biophys Acta 572:64-76

25. Kikkawa Y. Motoyama I:K. (iluck 1. 1968 Study of the lungs of fetal and newborn rabbits. Morphologic. biochemical and surface physical develonment. Am J Pathol 55:177-209

26. Kikkawa Y, Kaibara M. Motoyama I:K. Orzalesi MM Cook (D) 1971 Morphologic development of fetal rabbit lung and its acceleration with cortisol Am J Pathol 62:423-442

27. Keichlinc 1.D), (iiannopoulas 1981 Hormonal regulation of fetal rabbit lung development in organ culture. Fed Proc 40)407(abstr)

28. Phelps DS, (iiannopoulos (; 1984 Effect of dexamethasone on the synthesis of specific proteins in fetal rabbit lung in vivo and in organ culture. Fxp L.ung Res 7:195-210

29. Von Neergaard K 1929 Neue auffassungen iiber einen grundhegriff der atemmechanik. Dic retraktionskralt der lunge abhangig von der obertachen spannung in den alveolin Z (iesamte Kxp Med 66:373-394

30. Fiascone J Jacobs II. Mova E. Mercurio M. I. ima I) 1986 Differential effects of betamethasone on alveolar surfactant and lung tissuc of fetal rabbits. Pediatr Res 20:428A(abstr)

31. Fiascone JM, Jacobs IIC. Mova FR. 1 ima I)M. Mercurio MR 1987 Antenatal betamethasone exposure increases the saline compliance of fetal rabbit lungs. Pediatr Res 21:501 A(abstr)

32. Oyarzun MJ. (lements JA. Baritussio A 1980) Ventilation enhances pulmonar alveolar clearance of radioactive dipalmitoyl phosphatidylcholine in liposomes. Am Rev Respir Dis 121:709-72

33. Jobe AM. Ikegami M. Jacobs H, Jones S 1984 Surfactant and pulmonary blood flow distributions following treat ment of premature lambs with natural surfactant 3 ( Clin Invest 73:848-856

34. Iachman B, (irossman (i. Freyse J, Rohertson B 1981 I.ung-thorax compliance in the artificially ventilated premature rabbit neonate in relation to variation in inspiration:expiration ratio. Pediair Res 15:8.33-838

35. Jobe $\wedge$ M Ikegami M Jacobs HIC Jones SJ 1983 Surfactant pool sizes and severity of respiratory distress syndrome in prematurely delivered lambs. Am Rev Respir Dis 127:751-755

36. Jobe A Kirkpatrick F: (iluck 1 1978 L abeling of phospholipids in the surfictant and subcellular fractions of rabbit lung. J Biol (bem 253:3810-3816

37. Bartlett (iR 1959) Phosphorous assay in column chromatography. I Biol (hem $234: 466-408$

38. I.owry OH. Rosebrough NJ. Farr Al.. Randall R.I 1951 Protein measurement with the folin phenol reagent. J Biol (hem 193:265-275

39. Bland RD. MeMillan DD Bressack MA. Done $\mathrm{L} 1980$ (cearance of liquis from lungs of newborn rabbits. I $A$ ppl Phosiol +4:171-177

40. Nielsen HC. Torday IS 1983 Anatom of fetal rabbit gonads and the seang of fetal rabbits. I ab Anim $17: 148-150$

41. Possmayer F, Casola P. (han F, Hill S. Metcaife II. Stewart-D)haam PJ Wong T Las Heras J (iammal EB Harding P(iR 1979) (ilucocorticoid induction of pulmonary maturation in the rabbit ferus. Biochim Biophs Acta $574: 197-211$

42. Carson SH, Taeusch HW. Avery MI: 1973 Inhibition of lung cell division atte hydrocortisone injection into fital rabbits. J Appl Physiol .34:660)-60.3

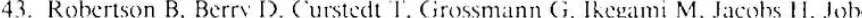
A. Jones $S 1985$ I cakage of protein in the immature rabbit lung: effect of surfactant replacement. Respir Physiol 61:26,5-276

44. Oulton M. Fraser M. Dolphin M. Faulkner (i 1986 Quantification of surfactan pool sizes in rabbit lung during perinatal development. J I ipid Res 27:60)? 612

45. Jacobs $H$ Jobe A ftegami M. Jones $S 1985$ Accumulation of alveolar surtactant following delivers and ventilation of premature lambs. Fap I ung Res $8: 125-140$

46. Ikegami M. Berry D. Flkady T. Pettenazzo A. Scidner S. Jobe A 198 Corticosteroids and surfactant change lung function and protein leaks in the lungs of ventilated preterm rabbits. J Clin Invest 79):1371-1.378

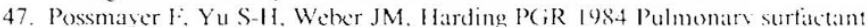
Can J Biochem (ell Biol 6?21121-1133

48. Kwong M. Egan 1: Votter $\mathrm{R} 1987$ Sinergistie response of antenatal betamethasone and tracheat instillation of calf lung surfactamt extract at birth Pediatr Res 21:458 A(ahstr) 